\title{
用“锌”看世界
} 仪器分析实验课程思政建设的探索

\author{
兰景凤 $1,{ }^{*}$, 王威 ${ }^{2}$, 沈永雯 ${ }^{1}$, 樊衍昕 ${ }^{2}$, 俞娥 ${ }^{1}$, 李莲花 ${ }^{1}$, 陆广农 ${ }^{1}$ \\ 1 化学国家级实验教学示范中心(兰州大学), 兰州 730000 \\ 2 兰州大学化学化工学院, 兰州 730000
}

摘要: 在新时代背景下, 高等教育要紧扣时代脉搏, 理清教育方向, 将大型分析仪器实验教学与祖国的需要连接起 来, 才能将储备的高科技人才 “人尽其才, 物尽其用, 地尽其利, 货尽其通” 。原子吸收光谱法测定毛发中的微量 元素锌的实验结合目前社会热点聚焦问题和历史重要事件, 在充分发挥实验教学的优势下, 将思政教育巧妙地融合 进仪器分析实验课程, 从能力培养、知识传授、价值观影响等三个方面对学生进行培养和教育, 探索高校专业实验 课的课程思政教育, 在实践中获得了满意效果。

关键词：仪器分析实验；课程思政；人尽其用；原子吸收光谱

中图分类号: G64; O6

\section{Looking at the World with "Zinc": Exploration on Course Ideology and Politics Construction of Instrumental Analysis Experiment}

\author{
Jingfeng Lan ${ }^{1, *}$, Wei Wang ${ }^{2}$, Yongwen Shen ${ }^{1}$, Yanxin Fan ${ }^{2}$, E Yu ${ }^{1}$, Lianhua Li ${ }^{1}$, Guangnong Lu 1 \\ ${ }^{1}$ National Experimental Teaching Demonstration Center of Chemistry (Lanzhou University), Lanzhou 730000, China. \\ ${ }^{2}$ College of Chemistry and Chemical Engineering, Lanzhou University, Lanzhou 730000, China.
}

\begin{abstract}
Under the background of the new era, higher education should closely follow the pulse of the times, clarify the direction of education, and connect the experimental teaching of large-scale analytical instruments with the needs of the motherland. Only in this way can the reserved high-tech talents "make the best use of their talents, materials, land and goods". The experiment of determination of trace element zinc in hair by atomic absorption spectrometry combines the current social hot issues and important historical events. Under the full play of the advantages of experimental teaching, ideological and political education is integrated into the instrument analysis experiment course. Students are trained and educated from three aspects of ability training, knowledge transmission and value influence, which explores the professional practice of colleges and universities the satisfactory effect of Ideological and political education in practice.
\end{abstract}

Key Words: Instrumental analysis experiment; Course ideology and politics; Making full use of people; Atomic absorption Spectrometry

教育是国之大计、党之大计, 承担着立德树人的根本任务 ${ }^{[1]}$ 。高校化学教学中的大型分析仪器 实验教学是培养大学生科研能力不可或缺的手段, 他们可以通过实验去验证从理论课上学来的知识,

收稿: 2020-10-26; 录用: 2020-11-12; 网络发表: 2020-12-11

”通讯作者, Email: lanjf@lzu.edu.cnl

基金资助：国家自然科学基金(21505062) 
也可以在实验的过程中思考, “动手、动脑加动心” 相得益彰的实验课教学在新时代下更迸发出蓬 勃生机。习近平总书记在2016年出席全国高校思想政治工作会议时发表重要讲话, 指出高校思想政 治工作关系到高校培养什么样的人、如何培养人以及为谁培养人这几个根本问题, 要坚持把立德树 人作为中心环节, 把思想政治工作贯穿教育教学全过程, 实现全程育人、全方位育人, 努力开创我 国高等教育事业发展新局面 ${ }^{[2]}$ 。2019年3月, 习近平总书记在学校思想政治理论课教师座谈会上明确 指出, 要坚持显性教育和隐性教育相统一, 挖掘其他课程和教学方式中蕴含的思想政治教育资源 ${ }^{[3]}$ 。 大型分析仪器的实验教学在教学方式上具有广泛的空间和时间调控性, 在充分挖掘实验教学中的思 政元素后, 将思想政治教育像 “盐于水” 一样, 巧妙地融合在实验教学里, 让学生在掌握科学知识 的同时增加爱国情愫, 实现从人生观、价值观、世界观三方面微渗透的效果。

兰州大学地处祖国西北、安于一地, 在西北的高等教育方面具有示范辐射作用; 学校在课程思 政方面积极响应号召, 早在2018年即开展全校范围内的课程思政比赛, 同时邀请全国名师到我校进 行教学培训, 积极引导全校教师将思想政治教育与专业课教育完美融合。化学化工学院在2019年开 展第一次全院课程思政比赛后, 曾会应老师代表学院以 “有机化学课的生物碱 [4]” 为参赛课程参加 学校课程思政比赛, 获得一等奖; 2020年9月, 学院举办第二次课程思政比赛, 笔者将近 2 年实验教 学方面的经验进行总结和凝练, 取得二等奖, 在得到教学委员会专家的指导后, 笔者运用实验教学 的优势, 将思政融入实验教学中, 教学过程中学生反响强烈, 课堂互动增多, 笔者在教学相长的过 程中获益良多。

大型仪器分析实验课覆盖化学、核学、生物学、地学、药学、大气学、资源环境学等几乎所有的理 工科专业, 因此, 做好仪器分析实验课的课程思政对理工科学生的思想政治教育将起到非常重要的作 用。如何完美地将思想政治教育与实验教学相结合就是此次课程思政建设探索的内容。

\section{1 因材施教, 开展课程思政}

大学教育是以习近平新时代中国特色社会主义思想为指导思想, 坚持社会主义办学方向, 落实立 德树人根本任务, 坚持教育为人民服务、为中国共产党治国理政服务、为巩固和发展中国特色社会主 义制度服务、为改革开放和社会主义现代化建设服务, 扎根中国大地办教育, 同生产劳动和社会实践 相结合, 加快推进教育现代化、建设教育强国、办好人民满意的教育, 努力培养担当民族复兴大任的时 代新人，培养德智体美劳全面发展的社会主义建设者和接班人 ${ }^{[1]}$ 。

当前的在校大学生 “自我意识” 强烈[5], 有关自身问题思考较多。比以往任何时代更多的媒体技术, 给学生提供了更广泛了解世界的平台, 他们面对的机会多、资源多。在大时代背景下, 大学生成为新时 代的主力, 他们是知识的受益者, 手机和电脑的普及对高校学生的学习、科研和生活产生很深的影响, 他们的思想更加多元化、发散化, 他们对新事物的好奇驱使他们运用理论知识、科学实验、文献搜集、 多媒体等手段去获取信息。

大学时期学生的人生观、价值观、世界观受外界影响较大, 可塑性较强 ${ }^{[6]}$, 教师在开展实验课教学 时应充分考虑授课对象的具体情况, 在平常的学习中渗透一些家国情怀、爱国情愫、工程伦理等信息, 结合自身教学手段和特色, 探索并把 “思想政治” 教育融入实验教学中去, 以期达到理论课与思想政治 教育的完美结合。

\section{2 结合课程特点, 细微处融入思想政治教育}

\section{1 从日常生活着手, 引起学生对本次课程的关注}

微量元素锌是人体必需的微量元素 ${ }^{[7-10]}$, 被称为 “生命之花” , 参与人体内 300 多种酶的合成。人 体内锌的总含量为 $2.5 \mathrm{~g}$ 左右, 主要分布在眼睛、毛发、骨骼和男性生殖器内, 缺锌会导致儿童生长发育 迟缓、注意力不集中、影响身高等; 成年人表现为手指起刺、手指甲白斑、地图舌、受伤后伤口愈合速 度减慢、自身免疫力下降等。在这一环节给学生以图片方式进行讲解。大多数学生在本环节会低头看 看自己的手指, 观察自身现象。这里可以给学生科普我国约有 1 亿人口受缺锌的影响, 其中 $30 \%-60 \%$ 为学龄儿童, 且主要分布在广大的农村地区 ${ }^{[11]}$ 。1982年在我国新疆喀什等地发现人体缺锌综合症 ${ }^{[12]}$ 。 
我国人群的饮食习惯多以含锌量较低的谷物类为主, 导致体内的锌含量较低, 一些以大量肉类为主 要食材的国家人群则锌含量则较高 ${ }^{[13]}$ 。通过这一环节, 引起学生对国家人民情况的关心、对锌元素的 兴趣, 同时抛出问题: 如何去表征锌元素呢? 大型分析仪器实验在教学大纲里需要积累大一、大二的 基础课程后才能开展相关实验, 学生已具有比较成熟的分析常量成分的方法和手段。他们会思考较之

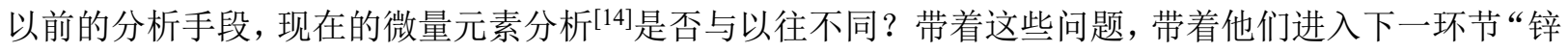
的几种不同分析方法”。

\section{2 总结不同分析手段对结果的影响}

在前人工作的基础上, 目前测量微量元素锌含量的方法有: 生化法、电化学分析法、原子吸收光谱 法 ${ }^{[14]}$ 。生化法: 消耗样品较多、准确度不高; 电化学分析法: 稳定性差、误差较大、对环境污染较大; 原子吸收光谱法: 分析准确、取样量少、检测速度快, 但仪器昂贵; 具体见表1。总结以上几种方法, 引导学生进行方法学比较, 对原子吸收光谱法初步认识和产生好奇, 在此基础上引导学生选择最佳的 分析方法来解决实际问题。

\section{表1 不同方法检测微量元素锌}

\begin{tabular}{ccccccc}
\hline 编号 & 检测方法 & 采样量 $/(\mathrm{g} /$ 次 $)$ & 检测限 $/\left(\mu \mathrm{g} \cdot \mathrm{g}^{-1}\right)$ & 重现性 & 程序 & 环境污染 \\
\hline 1 & 生化法 & 10.0 & $1.0 \times 10$ & 差 & 繁琐 & 大 \\
2 & 电化学分析法 & 10.0 & $1.0 \times 10^{2}$ & 差 & 繁琐 & 大 \\
3 & 原子吸收光谱法 & 0.2 & 0.5 & 好 & 简单 & 少 \\
\hline
\end{tabular}

\section{3 展开本次实验的目的}

结合上面的准备工作, 本次实验选定适合表征微量元素的方法: 原子吸收光谱法。实验目的一: 掌 握原子吸收光谱法的实验原理, 复习朗伯比尔定律在光谱学实验方面的理论计算; 目的二: 学会原子 吸收光谱仪(岛津AA6800型)的操作; 目的三: 学会毛发样品在测原子光谱时的前处理方法; 目的四: 运用原子吸收光谱仪测出自己头发中的锌含量。这里强调本次实验的目的, 既能增强学生解决问题的 主次能力, 也将思考问题的方式渗透在日常学习、科研和生活中, 鼓励学生找到解决实际问题最适宜 的方式。

\section{4 由历史引入实验原理}

从原子吸收光谱的发展历史, 渗透原子吸收光谱法的原理, 使学生了解原子吸收光谱历史的同时 理解原子吸收光谱法是检测暗线的一种方法 ${ }^{[14]}$ 。

1802年, 伍朗斯顿(W. H. Wollaston)在研究太阳连续光谱时, 发现了太阳连续光谱中出现的暗线。 1859年, 克希荷夫(G. Kirchhoff)与本生(R. Bunson)在研究碱金属和碱土金属的火焰光谱时, 发现钠蒸气 发出的光通过温度较低的钠蒸气时, 会引起钠光的吸收, 并且根据钠发射线与暗线在光谱中位置相同 这一事实, 断定太阳连续光谱中的暗线, 正是太阳外围大气圈中的钠原子对太阳光谱中的钠辐射吸收 的结果。1955年空心阴极灯出现; 1959年电热技术出现; 1965年氧化亚氮-乙炔火焰的出现。发展至今 的原子吸收光谱等一系列历史事件, 都可以帮助学生打开原子吸收光谱的神秘面纱。通过这些历史知 识的渗透, 激发学生对光谱学未来的期待, 引起他们对光谱学实验的兴趣(图1)。

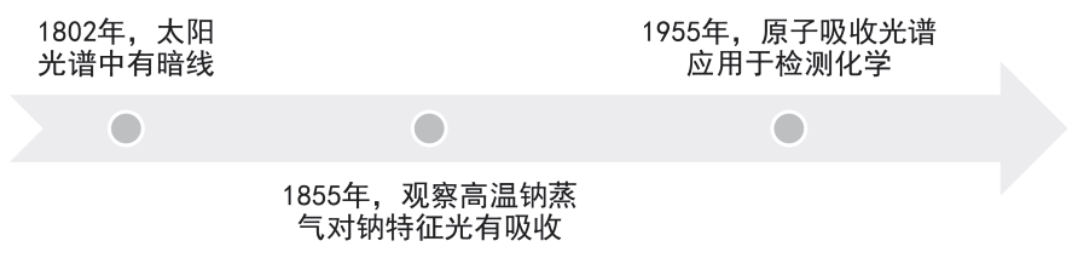

图1 原子吸收光谱的发展历史 
原子吸收光谱法是基于原子蒸气中的待测元素对其特征光谱有一定吸收, 根据特征光谱的辐射减 弱程度来判断待测元素含量, 其理论计算依据朗伯(Lamber)定律:

$$
I_{v}=I_{0} \mathrm{e}^{-K_{v} L} \Rightarrow \frac{I_{0}}{I_{v}}=\mathrm{e}^{-K_{v} L} \Rightarrow A=\lg \left(\frac{I_{0}}{I_{v}}\right)=0.4343 K_{v} L \Rightarrow A=K C
$$

由此得知: $A$ (吸光度)与 $C$ (待测样浓度)成 $K$ (系数)比例关系, 锌含量越高, 对应的吸光度就越大。 这里需跟学生强调: 一锐线光源(不可用连续光源)、二稀溶液(不可用浓溶液)这里可用牛毛的称量举例 (图2)。

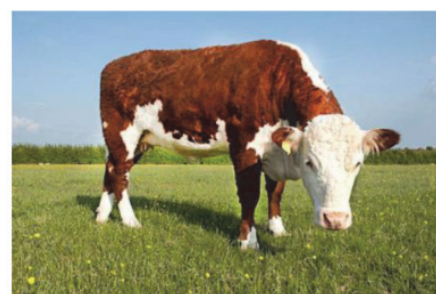

拔毛前称量: $500 \mathrm{~kg}$

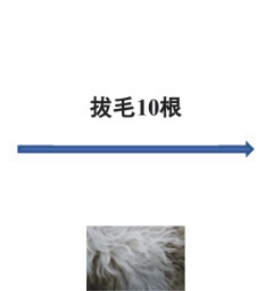

产生了 $\Delta m$

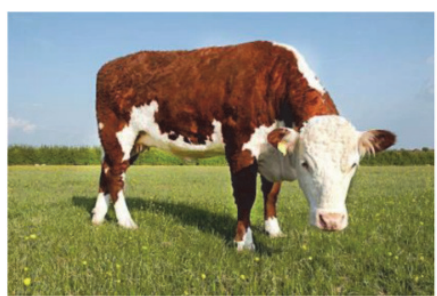

拔毛后称量: $500 \mathrm{~kg}$

图2 牛与牛毛举例示意图

在图2中, 可以看到: 在称量和减少牛毛的过程中, 产生 $\Delta m$, 但相比较一头重达 $500 \mathrm{~kg}$ 的牛来说, 减少的牛毛是不能显现的, 通过这张示意图即顺利展开了连续光源(牛)与锐线光源(牛毛)的区别, 在 检测锌元素特征光的发射能量变化时, 必须用牛毛级别的锐线光源才能得到满意的效果。学生在学 习原子吸收光谱原理的过程中也涉猎分析方法中差量法的应用局限性, 可拓展他们的发散思维。

\section{5 仪器构造讲解中插入其他分析仪器的优势, 拓展知识范围}

原子吸收光谱仪的构造比较复杂, 由四部分构成: 光源、原子化器、分光器、检测器。利用动 画、插图对仪器外观与内部构造进行对比理解和学习(图3)。

在图3中, 将原子吸收光谱仪的每一个部件都进行剖析, 充分利用已淘汰老旧仪器的部分部件, 如: 能量很低已经不能用于检测的空心阴极灯, 给学生实物展示和讲解, 结合具体组件使学生掌握 内部光路走势, 也能更清楚直接地掌握每一个重要部分的结构。在此环节加入 “绿水青山就是金山 银山 ${ }^{[15] ”}$ 的环保理念, 探讨节约成本、耗材的多次使用, 培养学生的环保理念。

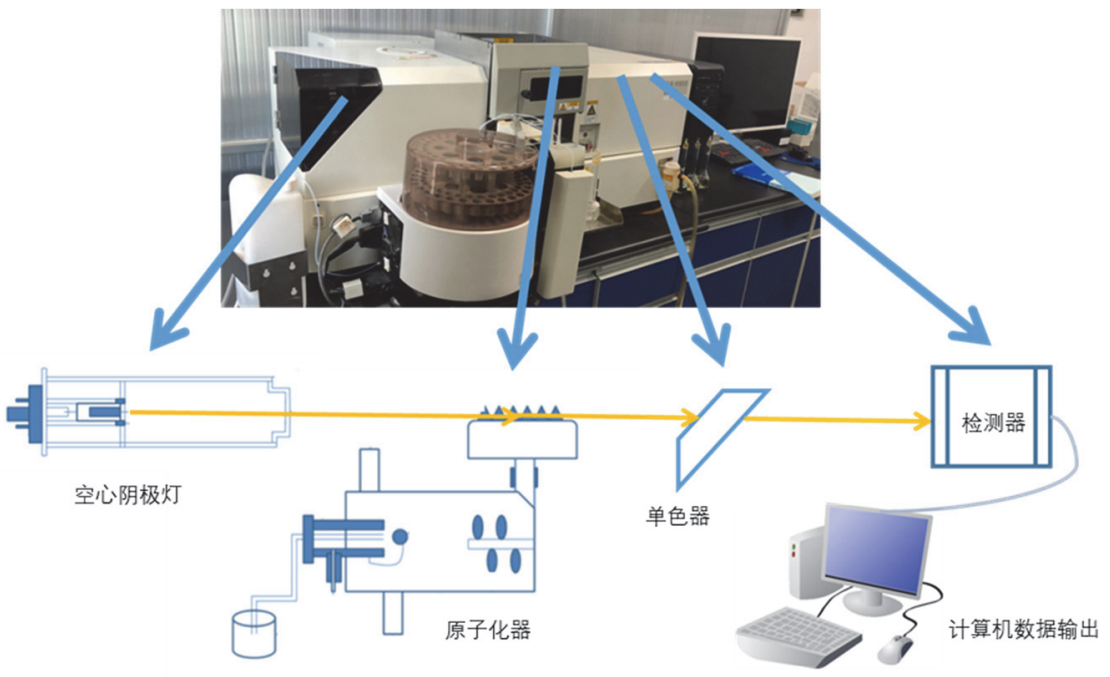

图3 原子吸收光谱仪实物及构造原理图 


\section{6 借助历史著名事件带着问题展开实验}

本实验涉及到毛发样品的处理, 在开始之前借助历史事件一一光绪死因展开实验。从学生普遍认 为的传说是否为事实提出问题：光绪是否被毒死的？让学生带着问题去寻找答案(图4)。
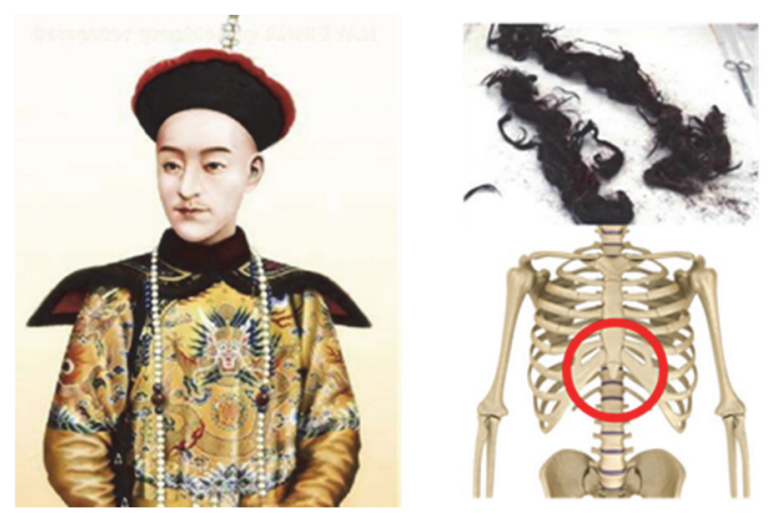

图4 光绪死因一一取发样和骨骼

通过光绪发样和骨骼发样测定结果的巨大差异: 在毛发根部没有发现砷, 但在其胃部附近的骨 骼(如图4红色圆圈部分)表面发现了超过人类致死量的200倍的砷。此研究结果验证了他的死因: 急 性中毒而死。这个几乎家喻户晓历史事件, 通过现代科学的验证进一步坐实历史传说是真的。讲解 这部分历史事件时引申到学生在以后的工作和学习中, 会有人走向质检岗位、法医学岗位、刑侦岗 位等, 需要掌握取样知识: 个体不一样、取样部位不一样、时间先后顺序不一样都会对检测结果产 生很大影响。学生表现出非常强烈的兴趣, 非常想知道他们自己毛发内的微量元素, 他们会带着好 奇全程参与整个实验中去。

在调动学生兴趣后, 及时引入本次实验处理毛发样品的顺序: 选取样品、洗涤干燥恒重后称量、 湿法消解、定容。具体操作流程如图5所示。

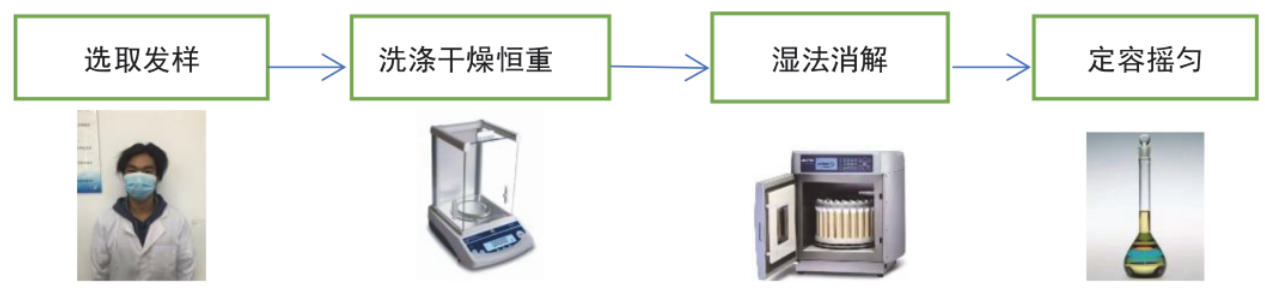

图5 毛发样品处理过程

在如图5所示的简单流程图里, 学生可以明确每步要完成的任务, 尤其采样环节, 学生非常积极 提取自己的发样, 做实验过程中参与度明显提高。在这个环节渗透了集体协作精神在社会工作中的 重要性, 强化学生相互学习、借鉴和提高的学习氛围。

\section{7 操作原子吸收光谱仪检测样品}

在操作原子吸收光谱仪过程中加入安全元素, 强调学习工作过程中遇到危险情况时需沉着应对, 多学习安全知识。具体操作时, 加入乙炔气的安全使用、个人对原子蒸气的防护等讲解。所有学习、 工作和生活的正常运行都离不开安全, 在仪器操作环节, 在学生动手的过程中, 结合不同类型的气 瓶展开乙炔气瓶的特征性介绍。通过对安全工作的详细分析, 加入爱岗敬业、严肃认真等社会主义 正能量思想政治教育。

\section{8 实验结果的讨论, 举学生身边的例子}

加入历年统计数据并进行比较, 引入人们生活水平提高相关内容。笔者将近 10 年的数据库进行 整理展示给学生, 数据采集对象中既有他们的上一级师兄师姐, 也有他们同年级的同学, 尤其是将 
最近一年内学生的数据结果(表2、表3)进行分析后, 特别列举出的检测对象是他们身边熟悉的同学、 舍友(图6), 引导学生觉察锌的含量和他们的生活关系密切, 激起他们对本次实验的好奇心, 并能主 动在课后进行延展学习。

表2 不同性别学生的含锌量(各50位)

\begin{tabular}{ccc}
\hline 性别 & 男 & 女 \\
\hline 平均锌含量 $/\left(\mu \mathrm{g} \cdot \mathrm{g}^{-1}\right)$ & 181.1 & 202.4 \\
\hline
\end{tabular}

表3 锌含量较少的学生个体

\begin{tabular}{cccc}
\hline 特征 & 饮食偏素 & 獒夜 & 运动少 \\
\hline 平均锌含量 $/\left(\mu \mathrm{g} \cdot \mathrm{g}^{-1}\right)$ & 165.0 & 136.1 & 140.7 \\
\hline
\end{tabular}

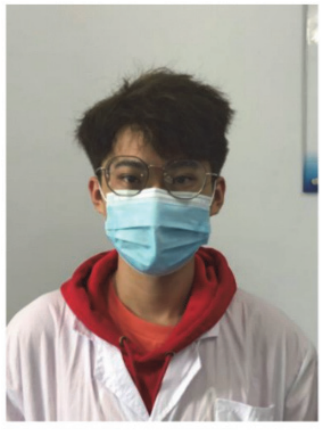

A 资发 $74.5 \mu \mathrm{g} / \mathrm{g}$

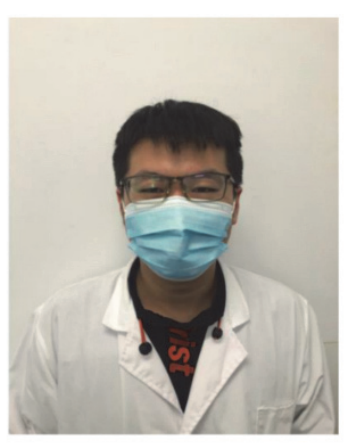

B 謷夜 $136.8 \mu \mathrm{g} / \mathrm{g}$

图6 两位毛发具有代表性的学生实际数据

从表2、表3可以看出: 男性比女性平均锌含量少 $20 \mu \mathrm{g} \cdot \mathrm{g}^{-1}$; 长期素食、獒夜、缺少运动等生活方 式都不利于锌的摄入和保留。

从图6中可以明显看到涊发学生A的特征, 此次检测的是该名学生涊发后的毛发, 锌含量为74.5 $\mu \mathrm{g} \cdot \mathrm{g}^{-1}$, 不能真实反映他的健康情况, 因此根据人体毛发的生长速度 $1.6 \mathrm{~cm} /$ 月, 强调他需在一个月以 后回来复检, 彼时检测的结果即能如实反映他身体的真实状况。图6中謷夜学生B的检测结果不容乐 观, 只有 $136.8 \mu \mathrm{g} \cdot \mathrm{g}^{-1}$, 是能真实反映他体内的锌含量的, 这时老师会给全组学生留一个悬念: 课后 查阅相关文献, 让身为同学的学生给予謷夜同学指导, 这个作业不但能激起学生对科学的好奇, 还 能增进学生之间的友谊, 让他们学习科学知识的同时, 带着 “帮助他人” 的目的去查阅资料, 鼓励 他们关心同学、友爱团结, 增加集体荣誉感。

此实验自2010年面对本科生开放, 有很多数据的积累, 笔者将近 10 年的数据进行整理汇总, 如图7 所示。

从图7可以看出, 在被检测对象平均年龄没有变化的情况下, 学生毛发中的锌含量随着时间推 移在不断增加: 男生头发中锌含量由 2010 年 $160.8 \mu \mathrm{g} \cdot \mathrm{g}^{-1}$ 增加至 2020 年的 $181.1 \mu \mathrm{g} \cdot \mathrm{g}^{-1}$; 女生由 2010 年 $173.6 \mu \mathrm{g} \cdot \mathrm{g}^{-1}$ 增加至 2020 的 $202.4 \mu \mathrm{g} \cdot \mathrm{g}^{-1}$ 。近年来通过国家和各级政府的不断努力, 我国人民的身体素 质在不断增强, 人体缺锌状况在不断改善。

这个环节是学生讨论问题最多的, 他们将自己的检测结果与这些大数据统计的结果进行比较, 并且开始根据自身的一些生活习惯进行对照, 引起他们对微量元素检测的浓厚兴趣, 这时鼓励他们 多查阅文献, 表述检测机理以及实验步骤可从学校网上学习, 并利用学校提供的如图8所示的线上资 源(https://vpnx.lzu.edu.cn/http/77726476706e69737468), 继续学习, 进一步巩固他们学习的效果。 


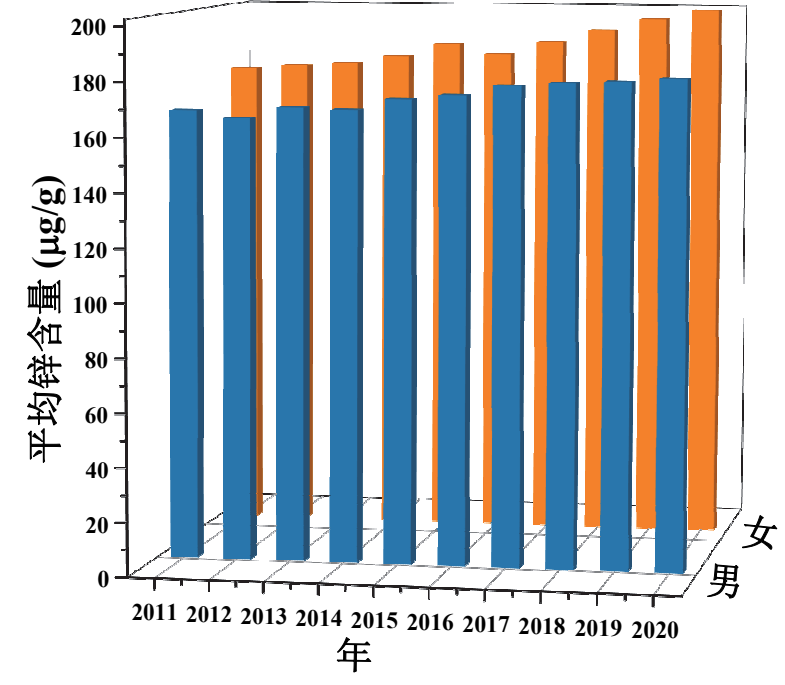

图7 2010至2020年收集的男性、女性毛发中的锌含量

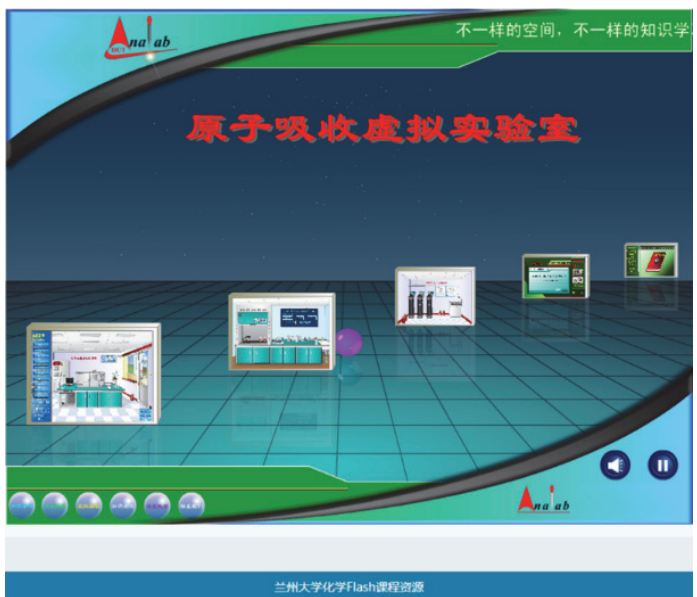

图8 原子吸收光谱线上资源示意图

\section{9 学生对课程思政的反馈}

笔者经过 2 年的课程思政探索, 面对 774 名学生开展本次实验教学, 学生对每一次的实验教学更 有期待, 他们的投入度也由原来的只求分数转变为现在的想去学、要去学、期待去学。从学生的眼 神和课堂互动来看, 他们对实验的专注度提高显著, 并且在课后线上实验课件中学习的热情大大增 强。教师在课后收到学生对实验相关细节的问题反馈较之之前提高显著, 学生的问题由原来仪器原 理的部分明显向仪器构造、方法拓展等方面增多。

\section{3 结语}

在学校没有进行课程思政建设之前, 教师没有意识到学生对知识的掌握是需要情景协助进行才 能达到完美效果的, 因此在实验教学中只一味地将理论知识如何结合实践知识作为工作重点, 也没 有意识到潜移默化的思政教育对专业课实验来说就像一把盐和一碗没有盐的水之间是会完美结合 的, 学生学得有滋有味、教师在教育中也会不断思考教学意义、教学方法。通过本次用 “锌” 看世 界的课程思政建设, 教师除在实验教学方法上丰富了很多实操的技巧, 同时在思想理论水平方面也 得到很大提升; 作为授课对象的学生在本次课程具体改革中受益良多, 对于激起他们科学研究的热 情起到非常大的助益。在大型分析仪器实验教学中实施 “课程思政”, 充分发挥化学实验课程的育 德育人功能, 对培养理工科学生的家国情怀、生态意识、科研视野等科学素养具有重要意义。

\section{参 考 文 献}

[1] 关于深化新时代学校思想政治理论课改革创新的若干意见. [2019-08-14]. http://www.gov.cn/zhengce/2019-08/14/content_5421252.htm

[2] 把思想政治工作贯穿教育教学全过程开创我国高等教育事业发展新局面. [2016-12-09].

http://cpc.people.com.cn/n1/2016/1209/c64094-28936173.html

[3] 中共中央国务院关于全面深化新时代教师队伍建设改革的意见. [2018-01-20]. http://www.moe.gov.cn/jyb_xwfb/xw_zt/moe_357/jyzt_2018n/2018_zt03/

[4] 段戴平, 曾会应. 大学化学, 2021, 36 (3), 2004044.

[5] 张变香. 大学化学, 2020,35 (7), 44.

[6] 马亚鲁, 马晓飞, 田昀, 秦学, 高洪苓, 刘华姬, 鲁凡丽, 王晓东, 王兴尧, 李丹峰, 等. 大学化学, 2020, 35 (8), 48.

[7] 石荣丽, 邹春琴, 张福锁. 广东微量元素科学, 2006, 13 (7), 1. 
[8] Demment, M. W.; Young, M. M.; Sensenig, R. L. J. Nutr. 2003, 133, 3879.

[9] Gibson, R. Proc. Nutr. Soc. 2006, 65, 51.

[10] 陈文强. 微量元素与健康研究, 2006, 23 (4), 62.

[11] Ma, G.; Jin, Y.; Li, Y.; Zhai, F.; Kok, F.; Jacobsen, E.; Yang, X. Public Health Nut. 2008, 11, 632.

[12] 兰晓霞. 国外医学(妇幼保健分册), 2003, 14 (1), 49.

[13] Frossard, E.; Bucher, M.; Machler, F. J. Sci. Food Agric. 2000, 80, 861.

[14] 张海霞, 王春明. 仪器分析. 兰州: 兰州大学出版社, 2018: 76-95.

[15] 中国共产党第十九次全国代表大会大会报告. [2017-10-18]. http://www.gov.cn/zhuanti/19thcpc/ 